\title{
Paradigm Shift of Carotid Body Paraganglioma Surgical Technique from Caudocranial to Craniocaudal Dissection: Analysis of Recent Literature
}

\author{
${ }^{1}$ Rajshekar Halkud, ${ }^{2}$ Ashok M Shenoy, ${ }^{3}$ A Nanjundappa, ${ }^{4}$ Purshottam Chavan, ${ }^{5} \mathrm{KT}$ Sidappa, ${ }^{6}$ SD Madhu \\ ${ }^{7}$ Siddharth Biswas, ${ }^{8}$ Sudhir M Naik
}

\begin{abstract}
Background: The classical Shamblin's classification predicts only vascular morbidity without remarking on the neurological morbidity, while the neurological damage increase with vessel ligation and reconstruction. A modified Shamblin's classification described by Luna-Ortiz with incorporation of the Hallett's zones of injury has been studied here.
\end{abstract}

Materials and methods: We present a case series analysis of carotid body paraganglioma managed in our institute. The study included 17 patients, 14 females and three males with a mean duration of presentation of 6.82 months. All were imaged with multislicer computed tomography angiography (CTA) and magnetic resonance angiography (MRA) for preoperative assessment and operated in the craniocaudal technique. The tumors were graded according to the modified Shamblin's criteria: grades I (2), II (13), IIIa (2), IIIb (0).

Results: All the preoperative assessment of grading matched with the intraoperative findings. External carotid artery (ECA) ligation was done in two cases, no internal carotid artery (ICA) ligation and reconstruction were done. Two cases of permanent damage to the 12th nerve, two vagal nerve weakness was seen. No stroke or mortality recorded. The tumor was confirmed on immunohistochemistry. The patients were followed up for 6 months to 5 years with a mean follow-up of 2.5 years.

Conclusion: Preoperative imaging assessment using multislicer computed tomography angiography (MSCTA) and MRA helps to measuring the circumferential vessel involvement in grade III tumors. So, a craniocaudal dissection with assessment of all the zones of injury reduced blood loss and minimized neurovascular complications.

Keywords: Carotid body paraganglioma, Zones of injury, Modified Shamblin's classification, ICA reconstruction.

How to cite this article: Halkud R, Shenoy AM, Nanjundappa A, Chavan P, Sidappa KT, Madhu SD, Biswas S, Naik SM.

\footnotetext{
${ }^{1,4}$ Associate Professor, ${ }^{2}$ Professor and Head, ${ }^{3,7}$ Professor

${ }^{5,6}$ Assistant Professor, ${ }^{8}$ Fellow

1-5,8 Department of Head and Neck Oncosurgery, Kidwai Memorial Institute of Oncology, Bengaluru, Karnataka, India

${ }^{6}$ Department of Radiodiagnosis, Kidwai Memorial Institute of Oncology, Bengaluru, Karnataka, India

${ }^{7}$ Department of Pathology, Kidwai Memorial Institute of Oncology Bengaluru, Karnataka, India
}

Corresponding Author: Sudhir M Naik, Fellow, Department of Head and Neck Oncosurgery, Kidwai Memorial Institute of Oncology, Bengaluru, Karnataka, India, Phone: 09916807109 e-mail: sud223@gmail.com
Paradigm Shift of Carotid Body Paraganglioma Surgical Technique from Caudocranial to Craniocaudal Dissection: Analysis of Recent Literature. Int J Head Neck Surg 2014;5(3):119-125.

Source of support: Nil

Conflict of interest: None

\section{INTRODUCTION}

Carotidbody paragangliomas(CBPs) arerare, slow-growing hypervascular tumors arising from paraganglionic cells of the carotid body usually located in the posteromedial wall of the common carotid artery (CCA) at the carotid bifurcation. ${ }^{1}$ The CBPs have infiltrating and dissemination potential which make them an indication for surgery at the time of diagnosis. ${ }^{1}$ The incidences of CBPs are on a rise as high resolution imaging pick up the quiescent ones accurately. ${ }^{1,2}$

Complications of CBP surgeries include cerebrovascular stroke with reported incidences of 0 to $11 \%$ and has been reported more in Shamblin III tumors. ${ }^{2,3}$ It is also reported without major manipulation of carotids like in Shamblin I, II tumors. ${ }^{4,5}$ Temporary to permanent complications of the cranial nerves the vagus and the hypoglossal range from 6.9 to $42 \%{ }^{5-7}$ So, Shamblin's classification overall grade the postoperative neurovascular complications depending on the size of the tumor and the encircling of the internal carotid artery (ICA) and external carotid artery (ECA). ${ }^{8,9}$ The cross-sectional analysis which decides the depth of the tumor into the vessel walls are not explained in this grading which decides the main procedures, like ECA ligation and ICA resection and interposition. ${ }^{3}$

The classical Shamblin's classification predicts only vascular morbidity without remarking on the neurological morbidity, while the neurological damage increase with vessel ligation and reconstruction. ${ }^{10}$ So, we attempt to review the modified Shamblin grading of Luna-Ortiz with description of the zones of dissection described by Hallett. ${ }^{11}$

\section{MATERIALS AND METHODS}

We present a case series analysis of carotid body paraganglioma managed in our institute. The study included 17 patients, 14 females (mean age $=31.28$ ), and 3 males 
(mean age $=41.33$ years) with a mean duration of presentation of 6.82 months. Ten had tumor on the left side and seven had on the right side. Overall mean age was 33.05 years. All the patients were diagnosed as carotid body paraganglioma (CBP) on clinical findings and confirmed on multislicer computed tomography engiography (MSCTA) and contrast MRI. All the tumors were classified according to the imaging based new Shamblin grading of Luna-Oritz (Figs 1 and 2). Fine needle aspiration was not done and clinically all the tumors were less than $5 \mathrm{~cm}$ size confirmed on MR analysis. No embolization was done in any of the cases. All the patients were operated with a classical curvilinear incision and craniocaudal dissection with bipolar cauterization. No Shamblin IIIb tumors were and two cases of IIIa were resected without ICA clamping or shunting or reconstruction. External carotid artery ligation was done in three cases flush with the bifurcation. Smaller liga clamps were applied to the feeders and spurters were cauterized. The average operative time was 158 minutes and average units of blood transfused was 0.4 units (Table 1 ).

\section{RESULTS}

All the preoperative assessment of grading matched with the intraoperative assessment, i.e. grade I (2), II (13), IIIa (2), IIIb (0). External carotid artery ligation was required in two cases with strict anticoagulation. None grade IIIb was encountered and so no ICA ligation and reconstruction were opted for. Two cases of permanent damage to the 12th nerve, two vagal nerve weakness was seen. No stroke or mortality recorded. The tumor was confirmed on immunohistochemistry where tumor was positive for synaptophysin and chromogranin, negative for cytokeratin and the sustentacular cells were positive S-100. The 10th nerve had complete recovery was seen over 3 months. The patients were followed up for 6 months to 5 years with a mean follow-up of 2.5 years. Follow-up was done 3 monthly for the 1 st year and 6 monthly later on (Table 2). ${ }^{7,8,12-15}$

\section{DISCUSSION}

Carotid body paragangliomas are painless, firm, slow growing, pulsatile mass, mobile horizontally than vertically. ${ }^{16}$ The surgical prognosis is better in younger and asymptomatic, medically fit individuals. ${ }^{10,17}$ The indications for surgery in older individuals above 60 are ambiguous as some believe it should be done in malignant changes only as the tumor is slow growing others believe that the tumor may progress and encroach skull base or lower CCA length and become inoperable. ${ }^{10,17}$

Shamblin classified the tumor based on its size, grade I which could be easily dissected away from the vessel wall, grade II which were intimately associated and compressed carotid vessels, but could be separated with careful subadventitial dissection and grade III were large and typically encased the carotid artery requiring partial or complete vessel resection and replacement. ${ }^{18}$ This clearly describes the risk in grade III associated with higher with cranial nerve and vascular injuries. ${ }^{3}$ A more operatively based classification was put forth by Luna-Ortiz et al, called the 'modified Shamblin grading'; grade I less than $4 \mathrm{~cm}$ in size with no surrounding or infiltrating the carotid and excision done without difficulty, grade II more than $4 \mathrm{~cm}$ in size with partial surrounding or infiltrating

Table 1: Complete analysis of the patients included in the study

\begin{tabular}{|c|c|c|c|c|c|c|c|c|c|c|}
\hline $\begin{array}{l}\text { Sl. } \\
\text { no. }\end{array}$ & Age & Sex & History & $\begin{array}{l}\text { Size } \\
(\mathrm{cm})\end{array}$ & $\begin{array}{l}\text { Tumor } \\
\text { side }\end{array}$ & $\begin{array}{l}\text { Modified Shamblin } \\
\text { classification (pre- } \\
\text { operative assessment) }\end{array}$ & $\begin{array}{l}\text { Operative } \\
\text { time } \\
\text { (minutes) }\end{array}$ & $\begin{array}{l}\text { Modified Shamblin } \\
\text { classification (post- } \\
\text { operative assessment) }\end{array}$ & $\begin{array}{l}\text { Follow- } \\
\text { up } \\
\text { (monthly) }\end{array}$ & $\begin{array}{l}\text { Intraoperative } \\
\text { blood transfusion } \\
\text { (pints) }\end{array}$ \\
\hline 1 & 35 & $\mathrm{~F}$ & 4 & $<4$ & $L$ & 1 & 120 & 1 & 7 & 0 \\
\hline 2 & 31 & $\mathrm{~F}$ & 8 & $<4$ & L & II & 130 & II & 13 & 1 \\
\hline 3 & 23 & $\mathrm{~F}$ & 6 & $<4$ & L & II & 130 & II & 24 & 0 \\
\hline 4 & 37 & $\mathrm{~F}$ & 11 & $<4$ & $\mathrm{R}$ & I & 110 & I & 11 & 1 \\
\hline 5 & 41 & $M$ & 6 & $<4$ & $\mathrm{~L}$ & II & 120 & II & 14 & 0 \\
\hline 6 & 35 & $\mathrm{~F}$ & 7 & $<4$ & $\mathrm{R}$ & II & 190 & II & 15 & 0 \\
\hline 7 & 27 & $\mathrm{~F}$ & 8 & $>4$ & $\mathrm{R}$ & Illa & 210 & Illa & 29 & 1 \\
\hline 8 & 34 & $\mathrm{~F}$ & 8 & $<4$ & $L$ & II & 190 & II & 16 & 0 \\
\hline 9 & 39 & $M$ & 6 & $<4$ & L & II & 180 & II & 46 & 0 \\
\hline 10 & 28 & $\mathrm{~F}$ & 4 & $<4$ & $\mathrm{R}$ & II & 180 & I & 48 & 1 \\
\hline 11 & 44 & M & 9 & $<4$ & L & II & 170 & II & 13 & 0 \\
\hline 12 & 31 & $\mathrm{~F}$ & 5 & $<4$ & L & II & 160 & II & 56 & 0 \\
\hline 13 & 33 & $\mathrm{~F}$ & 4 & $>4$ & L & Illa & 190 & Illa & 54 & 1 \\
\hline 14 & 29 & $\mathrm{~F}$ & 6 & $<4$ & $\mathrm{R}$ & II & 160 & II & 38 & 0 \\
\hline 15 & 35 & $\mathrm{~F}$ & 7 & $<4$ & $\mathrm{R}$ & II & 170 & II & 15 & 1 \\
\hline 16 & 23 & $\mathrm{~F}$ & 6 & $<4$ & L & II & 140 & II & 24 & 1 \\
\hline 17 & 37 & $\mathrm{~F}$ & 11 & $<4$ & $\mathrm{R}$ & II & 150 & I & 11 & 0 \\
\hline
\end{tabular}


Paradigm Shift of Carotid Body Paraganglioma Surgical Technique from Caudocranial to Craniocaudal Dissection

\begin{tabular}{|c|c|c|c|c|c|c|c|c|c|c|c|c|}
\hline Series & $\begin{array}{l}N \\
(\%)\end{array}$ & VII & $I X$ & $x$ & $X I$ & $X I I$ & $\begin{array}{l}\text { Permanent } \\
\text { CN injury }\end{array}$ & $\begin{array}{l}\text { ICA } \\
\text { ligation }\end{array}$ & $\begin{array}{l}\text { ICA } \\
\text { recons }\end{array}$ & $\begin{array}{l}E C A \\
\text { ligation }\end{array}$ & Stroke & Death \\
\hline $\begin{array}{l}\text { Koskas } \\
\text { et al } \\
(2009)\end{array}$ & 40 & $1(2.5 \%)$ & $3(7.5 \%)$ & $5(12.5 \%)$ & $2(5 \%)$ & $3(7.5 \%)$ & $4(10 \%)$ & $2(5 \%)$ & $7(18 \%)$ & $11(28 \%)$ & $1(3 \%)$ & 0 \\
\hline $\begin{array}{l}\text { Van der Bogt } \\
\text { et al (2008) }\end{array}$ & 111 & $1(1 \%)$ & $2(2 \%)$ & $3(3 \%)$ & $6(6 \%)$ & $24(24 \%)$ & $26(23 \%)$ & $1(1 \%)$ & $3(3 \%)$ & - & 0 & 0 \\
\hline $\begin{array}{l}\text { Papaspyrou } \\
\text { et al (2008) }\end{array}$ & 38 & - & - & - & - & $5(13 \%)$ & $5(13 \%)$ & $1(2.5 \%)$ & $1(2.5 \%)$ & - & $4(10 \%)$ & 0 \\
\hline $\begin{array}{l}\text { Makeieff } \\
\text { et al (2008) }\end{array}$ & 52 & - & - & $4(7 \%)$ & $2(3 \%)$ & $4(7 \%)$ & $4(7 \%)$ & $2(3 \%)$ & $5(9 \%)$ & $13(26 \%)$ & $2(3 \%)$ & 0 \\
\hline $\begin{array}{l}\text { Sajid et al } \\
(2007)\end{array}$ & 95 & $1(1 \%)$ & $1(1 \%)$ & $6(6 \%)$ & $2(2 \%)$ & $17(18 \%)$ & $18(19 \%)$ & 0 & 0 & 0 & $1(1 \%)$ & $1 \%$ \\
\hline $\begin{array}{l}\text { Smith et al } \\
(2006)\end{array}$ & 62 & - & - & $2(3 \%)$ & $2(3 \%)$ & $16(27 \%)$ & $16(27 \%)$ & 0 & $14(23 \%)$ & 0 & 0 & 0 \\
\hline $\begin{array}{l}\text { Ulster et al } \\
\text { (2011) }\end{array}$ & 29 & $5(17 \%)$ & 0 & 0 & $3(10 \%)$ & $9(31 \%)$ & $9(30 \%)$ & 0 & $7(23 \%)$ & $10(34 \%)$ & $1(3.3 \%)$ & 0 \\
\hline $\begin{array}{l}\text { Sen et al } \\
(2013)\end{array}$ & 7 & 0 & 0 & 0 & 0 & 0 & 0 & 0 & $1(14 \%)$ & $2(28 \%)$ & 0 & 0 \\
\hline $\begin{array}{l}\text { Prasad } \\
\text { et al (2011) }\end{array}$ & 5 & 0 & 0 & 0 & 0 & $1(20 \%)$ & 0 & 0 & 0 & 0 & 0 & 0 \\
\hline $\begin{array}{l}\text { Rajshekar, } \\
\text { Shenoy et al } \\
\text { (current } \\
\text { study) }\end{array}$ & 17 & 0 & 0 & 0 & 0 & $2(12 \%)$ & $2(12 \%)$ & 0 & 0 & $2(12 \%)$ & 0 & 0 \\
\hline
\end{tabular}

the carotid and excision done with difficulty. ${ }^{10}$ Grade III includes IIIa, IIIb = I, II or III infiltration to any carotid vessel more than $4 \mathrm{~cm}$ in size and intimately infiltrating or surrounding the carotid vessels with difficulty requiring vascular repair, sacrifice or vessel replacement. ${ }^{10}$

Multislicer computed tomography (CT) angiography remains the imaging of choice as it provides details about the location, size, shape, extent of the lesions and displays all round view of the tumor. ${ }^{19}$ A definite relation between the tumor and the carotid vessels and a definite information for a craniocaudal dissection can be mapped..$^{19}$ Finer details like tumor volume, dimensions, relation and distance of bone soft-tissue interface from the skull base are better seen than the obsolete conventional angiography. ${ }^{19}$ Key parameters of surgical interest are maximum diameter of the tumor in the craniocaudal direction, angle of circumferential encasement of ICA by the tumor, angle of splaying of the carotid bifurcation and distal free segment of ICA above the tumor. ${ }^{19}$ Noninvasive imaging has increased the incidental detection from 19 to $53 \%$ over the last two decades. ${ }^{12}$

Magnetic resonance imaging depicts a classical splaying the carotid bifurcation as a hyperintense mass on the T2-weighted sequences. ${ }^{20}$ Contrast MR studies depict early phase arterial enhancement with negative side display the tumor vascularity and bifurcation splaying, with specific crosssectional analysis of the depth of the tumor into the vessel walls. ${ }^{20}$ So, a paired imaging modality with MSCTA and MRI gives a comprehensive preoperative assessment of the CBP surgical anatomy. ${ }^{20}$
So angle of circumferential encasement, angle of splaying, maximum diameter in craniocaudal direction and the depth of the tumor invasion into the vessel walls determine the clinical risk criteria. ${ }^{20}$ The distal segment of the ICA is important to decide operative excision with ICA revascularization or the use of nonsurgical management. ${ }^{20}$

Magnetic resonance angiography also establishes patency of the circle of Willis, which helps shunting when CCA is clamped or reconstructed in Shamblin IIIb tumors. ${ }^{10}$

Arya et al reported MSCTA and MRA imaging especially with $3 \mathrm{D}$ reconstruction plays a major role in preoperative assessment of CBPs. ${ }^{21}$ An excellent correlation between cross-sectional MR imaging radiological pattern and intraoperative findings have been documented. ${ }^{21}$ They reported the modified Shamblin Luna-Ortiz classification based on the circumference of contact of tumor with ICA is more reliable intraoperatively than the tumor size itself. ${ }^{21}$ They defined the classification as Shamblin I: tumor encircling upto $180^{\circ}$ of ICA $(<4 \mathrm{~cm})$, Shamblin II: tumor encircling 180 to $270^{\circ}$ of ICA $(<4 \mathrm{~cm})$, Shamblin IIIa: tumor encircling more than $270^{\circ}$ of ICA $(>4 \mathrm{~cm})$, Shamblin IIIb (type I): partial infiltration of ICA and encircling upto $180^{\circ}(<4 \mathrm{~cm})$, Shamblin IIIb (type II): partial infiltration of ICA and encircling 180 to $270^{\circ}(<4 \mathrm{~cm})$, Shamblin IIIb (type III): partial infiltration of ICA and encircling more than $270^{\circ}(>4 \mathrm{~cm}) .{ }^{21}$ Also the circumferential contact with the ECA and CCA, the free segment of ICA are important for vascular reconstruction of carotid if resection done. ${ }^{21}$ 
Iafrati and O'Donnell have laid down a criteria for preoperative imaging which include; (a) to secure the diagnosis of CBP, (b) to define local tumor extension to anticipate the need for extended exposure or carotid resection potentially requiring endarterectomy, (c) to identify synchronous tumors either ipsilateral or in the contralateral carotid, (d) finally to determine of the need for preoperative tumor embolization. ${ }^{22}$

Carotid angiogram being invasive finds importance only with digital substraction when preoperative embolization are planned in grade III large tumors. ${ }^{23}$ Supraselectively, feeder vessel embolization carefully performed without reflex into the cerebral circulation helps shrinking the tumor and provides the much needed hemostasis. ${ }^{23}$ Surgical excision should be performed in 48 hours to minimize revascularization edema or a local inflammatory response. ${ }^{24}$ The preoperative embolization can be performed by ethanol or polyvinyl alcohol and not necessary in management of small tumors $<4 \mathrm{~cm} .{ }^{3}$ Rarely, angiogram is used to assess ICA invasion, to perform an ICA balloon occlusion test in occasions where ICA reconstruction is not possible and in IIIb tumors where ligation becomes necessary. ${ }^{25}$ Some studies reported preoperative embolization have no relation to the stroke incidences while ICA shunting, manipulation and reconstruction, ECA ligation and repair of injury are significantly related. ${ }^{13}$ They stated that careful preoperative planning in class II and III tumors with early division of ECA with minimal ICA manipulation reduced the stroke rate significantly rather than preoperative percutaneous embolization. $^{13}$

Usually, a curvilinear skin incision exposes the smaller tumor adequately but extension along the anterior border of the sternomastoid is needed in larger tumors to expose the lower extent. ${ }^{3,7}$ Hallett et al described the caudocranial dissection for CBP where no impetus on shunting and reconstruction was seen. ${ }^{11}$ The grade I, II $\mathrm{CBP}$ are approached by the small curvilinear incision from mentum to mastoid with exposure of the tumor. ${ }^{11}$ The proximal end of ECA and end just distal to the tumor margin of ICA was controlled for safe resection. ${ }^{11}$ The 12th nerve if adherent is dissected from the tumor surface and periadventitial plane along the carotid bifurcation is separated. ${ }^{11}$ The tumor is dissected upwards with temporary clamping below the carotid bifurcation. ${ }^{11}$ Tumor is freed from the ECA and the feeders are bipolarized reflected onto the ICA from where it is freed. p23 grade III tumors needed an extension to the classical curvilinear along the anterior border of the sternomastoid muscle. ${ }^{11}$ CBP encasing of the ECA, ICA and cranial nerves is defined. ${ }^{11}$ Similarly, the controls proximal ECA and distal ICA marked and the inferior extent exposed. ${ }^{11}$ The superior extent is exposed by identification of the mandibular branch of facial nerve and parotid. ${ }^{11}$ Also the stylohyoid and the posterior belly of digastric are divided for better exposure. ${ }^{11}$ Hypoglossal is mobilised up and ECA and its branches are ligated flush at the bifurcation and above the tumor which shrinks the tumor. ${ }^{11}$ Later the dissection is tried in the periadventitial plane along the ICA. ${ }^{11}$

The tumor anatomy was divided into three anatomic zones, zone I includes the carotid bifurcation and adjacent vagus nerve, zone II encompasses the ECA territory, the overlying hypoglossal nerve, and the underlying superior laryngeal nerve while zone III contains the ICA, the mandibular branch of the facial nerve, the proximal hypoglossal nerve, the upper vagus nerve, the pharyngeal branch of the vagus nerve, the spinal accessory nerve, and the glossopharyngeal nerve (Fig. 1). ${ }^{11}$ Most of the serious neurovascular injuries occur in this crowded zone III (Fig. 2). ${ }^{11}$ In all CBPs, the cranial nerves are loosely adherent to the tumor in all zones and can be easily freed, except the vagal paraganglioma. ${ }^{11}$ While clamping CCA or shunting the vagus may be injured in zone I but most of them are transient. ${ }^{11}$ Hypoglossal nerve can be easily freed of the tumor surface in zone II, while the superior laryngeal nerve is preserved by dissecting on the tumor surface. ${ }^{11}$ Zone III contains the ICA and many cranial nerves VII, IX, X and XII which needs the utmost care while dissection to prevent the neurovascular complications. ${ }^{11}$

Gordon et al described the subadventitial craniocaudal dissection through the avascular space between the vessels of the carotid system and the tumor. ${ }^{26,27}$ The controls of ECA and distal ICA was also stressed on with early ligation of the ECA and its branches in grade III tumors with necessary repair of the ICA with clamps and shunting. ${ }^{26,27}$ Van der Bogt et al reported decrease in vascularity of the tumor reduced perioperative morbidity. ${ }^{13,28}$ They advised craniocaudal dissection of the Shamblin II and III where the tumor feeder vessels are ligated before the tumor and internal carotid artery are manipulated. ${ }^{13,28}$ As the ascending pharyngeal artery branches are the main feeder vessels entering from the cranial side on the dorsal aspect of the tumor. ${ }^{13,28}$ Referred as the dissection zones III it is also the proximal site where the prominent neurological structures cross over. ${ }^{13,28}$ Early ligation of tumor of the prominent feeder vessels and less blood loss and identification of the adjacent cranial nerves before manipulation of CBG are the advantages of the craniocaudal approach. ${ }^{13,28}$ They reported $60 \%$ reduction in blood loss in the craniocaudal approach and also a lesser cranial nerve damage. ${ }^{13,28}$

The placement of this shunt through incision on the common carotid artery contributes to the adequatebleeding 


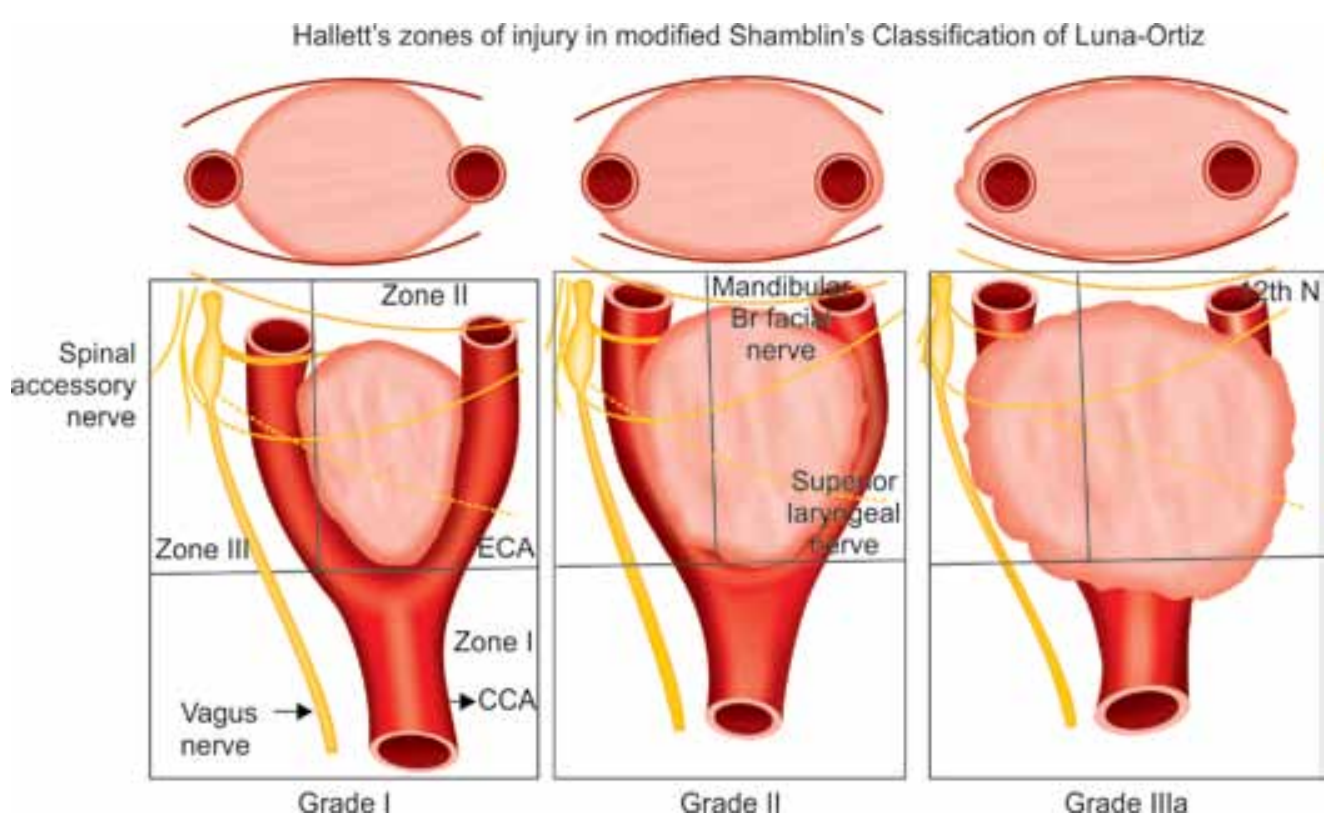

Fig. 1: Hallett's zones of injury in modified Shamblin grading grades I, II and IIla tumors

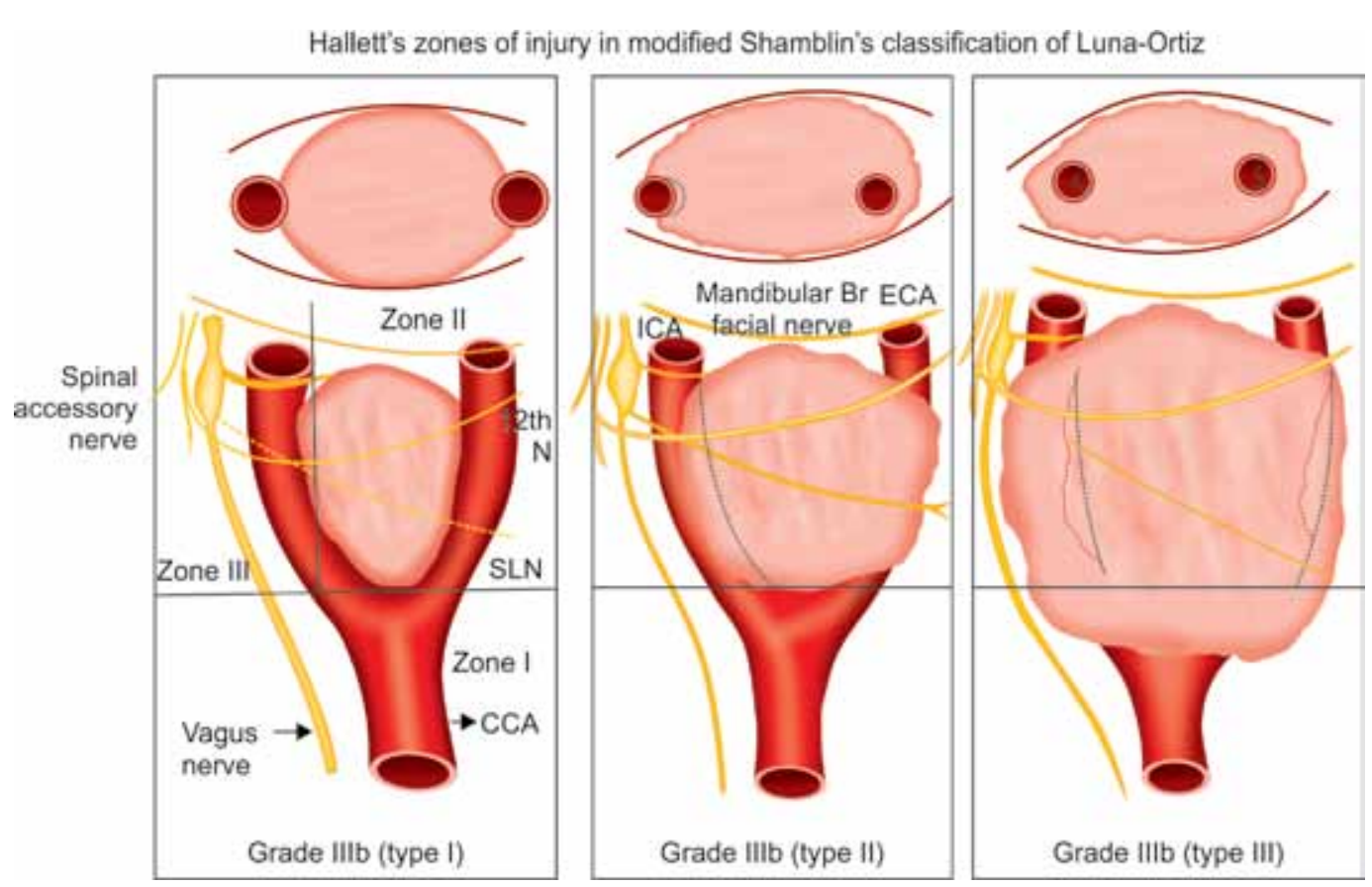

Fig. 2: Hallett's zones of injury in modified Shamblin grading grades IIIb, type I, II and III tumors

control from the common and internal carotid arteries as well as brain protection giving hemostasis while tumor dissection. ${ }^{27}$ The shunt is safer and effective in maintaining cerebral circulation and shrinks the tumor instantly by excluding the vascular supply of the ECA. ${ }^{27}$ Modified Shamblin grade IIIb tumors need excision and reconstruction using synthetic grafts or autologous saphenous vein grafts. ${ }^{10}$ Periodic duplex sonographic scanning to identify graft stenosis should be done in vessel reconstructed individuals. ${ }^{29}$

Sometimes larger tumors may need mandibular subluxation, reserved for large tumors that usually extend cranially, advancing the vertical ramus of the mandible forward by 2 to $3 \mathrm{~cm}$ transforming the normal triangular shaped operative field into a rectangular one, widening its apex, thus providing additional space for safe exposure and control of the distal ICA. ${ }^{30}$

Carotid reconstruction done for grade III had 7.5\% incidences of stroke, while due to ICA injury and thrombosis 0 to $16 \% .{ }^{11,31}$ Adequate anticoagulation is to be maintained or else clamping, ligation or reconstruction will cause cerebral ischemia. ${ }^{11,31}$ Carotid reconstruction needs intense monitored anticoagulation, neuromonitoring and selective shunting intraoperatively and antiplatelet use with ultrasound surveillance of the reconstruction postoperatively. ${ }^{11,31}$ Electroencephalography (EEG) monitored temporary carotid clamping, selective internal carotid shunting prevent incidences of stroke. ${ }^{11,31}$ 
Deliberate ECA ligation is not mandatory as preoperative embolization serves the purpose. ${ }^{12,32}$ Blood loss and transfusion rates have dropped down to an average $2200 \mathrm{ml}$ in Shamblin grade III tumors. ${ }^{12,32}$ Craniocaudal dissection where the hypoglossal is reflected up and the feeders are ligated and bipolarized gives more hemostasis than the classical Hallers method of caudocranial dissection exposing the bifurcation first. ${ }^{12,32}$ Hallet et al described the distal ICA as the most dangerous dissection zone because of its proximity to a number of cranial nerve $(\mathrm{CN}){ }^{11,33}$ Cranial nerve IX or $\mathrm{X}$ injury may lead to aspiration, so nasogastric feeding of PEG may be needed in some cases. ${ }^{11,33}$

Literature search suggests that $40 \%$ incidence of $\mathrm{CN}$ injury with CBP surgery while while permanent $\mathrm{CN}$ injury seen in 8 to $39 \%$ of patients (mean 20\%) which may include 7th nerve (marginal mandibular branch), 10th and 12th nerve. ${ }^{8,9,34,35}$ Mortality has been reported upto 5 to $13 \%$ in literature which may be due to poor preoperative planning and expertise. ${ }^{19,34,36}$ The modern surgical techniques have reduced the risk of postoperative stroke in carotid body paraganglioma resection to less than $5 \% .{ }^{27}$ We had no IIIb tumors and so lesser complications and a comparative analysis of the complications of the recent major studies are done (Table 1). ${ }^{7,8,12-15}$

\section{CONCLUSION}

Preoperative imaging assessment using MSCTA and MRA helps measuring the circumferential vessel involvement in grade III tumors. The knowing of luminal infiltration in IIIb added more preparation to procedure like ICA shunting, manipulation, reconstruction while adding to the assessment of risk criteria. While preoperative embolization and intraoperative shunting shrunk the tumor, it is the meticulous technique of craniocaudal dissection with early division of ECA with minimal ICA manipulation and reconstruction whenever necessary reduced the complications. Incidence of CBPs is more due to advanced imaging and can be managed by low neurovascular complications. The success rates have improved due to complete preoperative imaging, better surgical technique and intraoperative monitoring. So, a craniocaudal dissection with assessment of all the zones of injury reduced blood loss and minimized neurovascular complications.

\section{REFERENCES}

1. Georgiadis G, Lazarides M, Tsalkidis A, et al. Carotid body tumor in a 13-year-old child: case report and review of the literature. J Vascul Surg 2008;47(3):874-880.

2. Grotemeyer D, Loghmanieh SM, Pourhassan S, Sagban TA, Iskandar F, Reinecke P, et al. Dignity of carotid body tumors: review of the literature and clinical experiences. Chirurg 2009 Sep;80(9):854-863.
3. Albsoul NM, Alsmady MM, Al-Aardah MI. Carotid body paraganglioma management and outcome. Eur J Sci Res 2009;37(4):567-574.

4. Singh D, Pinjala R, Reddy R, Vani P. Management for carotid body paragangliomas. Interactive Cardio Vascular and Thoracic Surgery 2006;5(6):692-695.

5. Tayyab M, Khan M, Sophie Z. Presentation and management of carotid body tumors. J Pak Med Assoc 2003;53(7):306-310, 312.

6. Ridge B, Brewster D, Darling R, Cambria R, LaMuraglia G, Abbott W. Familial carotid body tumors: incidence and implications. Annals of Vascular Surgery 1993 Mar;7(2):190-194.

7. Makeieff M, Raingeard I, Alric P, et al. Surgical management of carotid body tumors. Ann Surg Oncol 2008;15(3):2180-2186

8. Sajid MS, Hamilton G, Baker DM. On behalf of joint vascular research G: a multicenter review of carotid body tumor management. Eur J Vasc Endovasc Surg 2007;34(2):127-130.

9. Netterville J, Reilly K, Robertson D, Reiber M, Armstrong W, Childs P. Carotid body tumors: a review of 30 patients with 46 tumors. Laryngoscope 1995 Feb;105(2):115-126.

10. Luna-Ortiz K, Rascon-Ortiz M, Villavicencio-Valencia V. Carotid body tumors: review of a 20-year experience. Oral Oncol 2005;41(1):56-61.

11. Hallett JW, et al. Trends in neurovascular complications of surgical management for carotid body and cervical management paragangliomas: a 50-year experience with 153 tumors. J Vascul Surg 1988;17(7):284-291.

12. Kakkos SK, Reddy DJ, Shepard AD, Lin JC, Nypaver TJ, Weaver MR. Contemporary presentation and evolution of management of neck paragangliomas. J Vascul Surg 2009 June;49(6):1365-1373.

13. van der Bogt KEA, van Baalen JM, Hamming JF. Risk factors for stroke during surgery for carotid body tumors. World J Surg 2011 Dec;35(12):2829-2830.

14. Smith JJ, Passman MA, Dattilo JB, Guzman RJ, Naslund TC, Netterville JL, et al. Carotid body tumor resection: does the need for vascular reconstruction worsen outcome? Ann Vasc Surg 2006;20(4):435-439.

15. Prasad SC, Thada N, Pallavi, Prasad KC. Paragangliomas of the head and neck: the KMC experience. Ind J Otolaryngol Head Neck Surg 2011 Jan;63(1):62-73.

16. Leonetti J, Donzelli J, Littooy F, Farrel B. Perioperative strategies in the management of carotid body tumors. Otolaryngol Head Neck Surg 1997;117(1):111-115.

17. Rodriguez-Cuevas S, Lopez-Garza J, Labastida-Almendaro S. Carotid body tumors in inhabitants of altitudes higher than 2000 meters above the sea level. Head Neck 1998;20(5):374-378.

18. Lotina S, Davidoviæ L, Havelka M, Vojnoviæ B, Neškoviæ V, Stojanov P, Kecman N. Carotid body tumors. J Serbian Med Soc 1997;125(3):278-284.

19. Wang SJ, Wang MB, Barauskas TM, Calcaterra TC. Surgical management of carotid body tumors. Otolaryngol Head Neck Surg 2000;123(3):202-206.

20. Neves F, Huwart L, Jourdan G, et al. Head and neck paragangliomas: value of contrast-enhanced 3D MR angiography. Am J Neuroradiol 2008;29(3):883-889.

21. Arya S, Rao V, Juvekar S, Dcruz AK. Carotid body tumors: objective criteria to predict the Shamblin group on MR imaging. Am J Neuroradiol 2008 Aug;29(7):1349-1354.

22. Iafrati MD, $\mathrm{O}^{\prime}$ Donnell TF Jr. Adjuvant techniques for the management of large carotid body tumors: a case report and review. Cardiovasc Surg 1999;Jan;7(1):139-145. 
23. Robison JG, Shagets FW, Beckett WC, Spies JB. A multidisciplinary approach to reducing morbidity and operative blood loss during resection of carotid body tumor. Surg Gynecol Obst 1989;168(3):166-170.

24. Balatsouras DG, Eliopoulos PN, Economou CN. Multiple glomus tumors. J Laryngol Otol 1992 Jun;106(6):538-543.

25. Rao AB, Koeller KK, Adair CF. From the archives of the AFIP. Paragangliomas of the head and neck: radiologic-pathologic correlation. Armed Forces Institute of Pathology. Radiographics 1999 Nov-Dec;19(6):1605-1632.

26. Westerband A, Hunter GC, Cintora I. Current trends in the detection and management of carotid body tumors. J Vasc Surg 1998;28(2):84-93.

27. Defraigne JO, Sakalihassan N, Antoine P, Thiry A, Limet R. Carotid chemodectomas. Experience with nine cases with reference to preoperative embolization and malignancy. Acta Chir Belg 1997;97(4):220-228.

28. Van den Berg R, Wasser MN, van Gils AP, van der Mey AG, Hermans J, van Buchem MA. Vascularization of head and neck paragangliomas: comparison of three MR angiographic techniques with digital subtraction angiography. Am J Neuroradiol 2000 Jan;21(1):162-170.

29. Zabel A, Milker-Zabel S, Huber P, Schulz-Ertner D, Schlegel W, Wannenmacher M, Debus J. Fractionated stereotactic conformal radiotherapy in the management of large chemodectomas of the skull base. Int J Radiat Oncol Biol Phys 2004 Apr 1;58(5):1445-1450.

30. Dossa C, Shepard AD, Wolford DG, Reddy DJ, Ernst CB. Distal internal carotid exposure: a simplified technique for temporary mandibular subluxation. J Vasc Surg 1990 Sep; 12(3):319-325.

31. Bishop GB Jr, Urist MM, el Gammal T, Peters GE, Maddox WA. Paragangliomas of the neck. Arch Surg 1992;23(3): 1441-1445.

32. Plukker JT, Brongers EP, Vermey A, Krikke A, van den Dungen JJ. Outcome of surgical treatment for carotid body paraganglioma. Br J Surg 2001;388(10):1382-1386.

33. Rosenbloom M, Friedman SG, Lamparello PJ, Riles TS, Imparato AM. Glossopharyngeal nerve injury complicating carotid endarterectomy. J Vasc Surg 1987 Mar;5(3):469-471.

34. Dickinson PH, Griffin SM, Guy AJ, McNeill IF. Carotid body tumour: 30 years experience. Br J Surg 1986;73(1):14-16.

35. Dimakakos PB, Kotsis TE. Carotid body paraganglioma: review and surgical management. Eur J Plast Surg 2001;24(2): 58-65.

36. Papaspyrou K, Mann WJ, Amedee R. Management of head and neck paragangliomas: review of 120 patients. Head Neck 2009;31(3):381-387. 